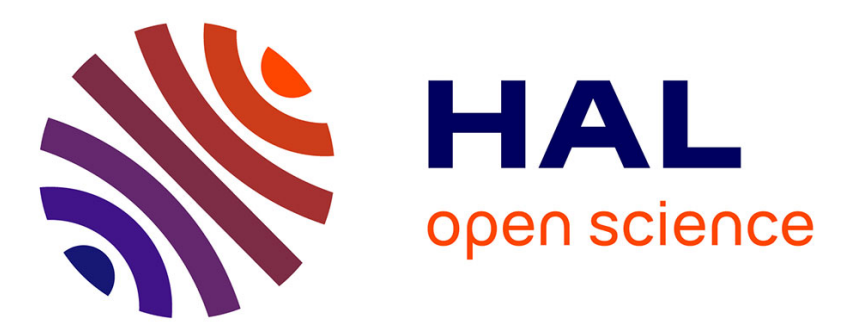

\title{
Big-Fish-Little-Pond Effects on Gymnastics Self-concept: Social Comparison Processes in a Physical Setting
} Julien Chanal, Herbert W. Marsh, Philippe Sarrazin, Julien Bois

\section{To cite this version:}

Julien Chanal, Herbert W. Marsh, Philippe Sarrazin, Julien Bois. Big-Fish-Little-Pond Effects on Gymnastics Self-concept: Social Comparison Processes in a Physical Setting. Journal of Sport and Exercise Psychology, 2005, 27 (1), pp.53-70. 10.1123/jsep.27.1.53 . hal-00388999

\section{HAL Id: hal-00388999 https://hal.science/hal-00388999}

Submitted on 28 May 2009

HAL is a multi-disciplinary open access archive for the deposit and dissemination of scientific research documents, whether they are published or not. The documents may come from teaching and research institutions in France or abroad, or from public or private research centers.
L'archive ouverte pluridisciplinaire HAL, est destinée au dépôt et à la diffusion de documents scientifiques de niveau recherche, publiés ou non, émanant des établissements d'enseignement et de recherche français ou étrangers, des laboratoires publics ou privés. 


\title{
Running Head: BIG-FISH-LITTLE-POND EFFECT
}

Big-Fish-Little-Pond Effects on Gymnastics Self-concept:

Social Comparison Processes in a Physical Setting

\author{
Julien P. Chanal
}

University J. Fourier of Grenoble, France

Herbert W. Marsh

SELF Research Centre, University of Western Sydney, Australia

Philippe G. Sarrazin and Julien E. Bois

University J. Fourier of Grenoble, France

Journal of Sport and Exercise Psychology, 27(1), 53-70.

Author Notes

Julien Chanal, Philippe Sarrazin and Julien Bois are with the Laboratory "Sport et Environnement Social", Université J. Fourier, Grenoble, France. Herbert Marsh is with the SELF Research Centre and the School of Psychology at the University of Western Sydney, Australia. We would like to thank Aina Chalabaev and Damien Tessier who helped in the data collection of the study. Correspondence concerning this article should be addressed to Dr. Philippe Sarrazin, "Laboratoire Sport et Environnement Social" E.A. 540, UFRAPS - Université J. Fourier, Grenoble I. BP 53 - 38041 Grenoble Cedex 9 - France. E-mail: philippe.sarrazin@ujf-grenoble.fr 


\begin{abstract}
In sport/exercise contexts, individuals use the performances of others to evaluate their own competence. In big-fish-little-pond effect (BFLPE) in educational settings, academic self-concept is positively predicted by one's own academic achievement but negatively predicted by the average achievement of others in one's school or class. Participation in programs for academically gifted students leads to lower self-concepts. In apparently the first test of the BFLPE in the physical domain, multilevel models of responses by 405 participants in 20 gymnastics classes supported these predictions. Gymnastics self-concept was positively predicted by individual gymnastics skills, but negatively predicted by class-average gymnastics skills. The size of this negative BFLPE grew larger during the 10week training program (as participants had more exposure to the relative performances of others in their class), but did not vary as a function of gender, age, or initial gymnastics skills.
\end{abstract}

KEY WORDS: Physical Self-concept, Big-Fish-Little-Pond-Effect, Gymnastics, Multilevel analysis. 


\section{Big-Fish-Little-Pond Effects on Gymnastics Self-concept: \\ Social Comparison Processes in a Physical Setting}

Self-concept is one of the most important constructs in the social sciences, as demonstrated by the regularity/consistency with which self-concept enhancement is identified as a major focus of concern in diverse settings (e.g., Branden, 1994; Marsh \& Craven, 1997). In addition to being an important outcome variable, a positive self-concept also facilitates the attainment of a number of positive outcomes (see Weiss \& Ebbeck, 1996; Weiss \& Ferrer-Caja, 2002 for reviews) such as perceptions of control (e.g., Weigand \& Broadhurst, 1998), motivational orientation (e.g., Weiss \& Horn, 1990), global self-esteem (e.g., Weiss, McAuley, Ebbeck \& Wiese, 1990), enjoyment (e.g., Scanlan \& Simons, 1992), attraction to physical activity (e.g., Brustad, 1988) and decrease in anxiety and stress (e.g., Scanlan, Stein, Ravizza, 1991). The need to think and feel positively about oneself, and the profound benefits of these positive cognitions on choice, planning, and subsequent accomplishments transcend traditional disciplinary barriers. Individuals are likely to accomplish more if they feel competent in what they do, are self-confident, and feel positively about themselves (Marsh \& Craven, 1997). For example, Marsh (2002) reported that elite athletic self-concept contributed to the prediction of the performances of elite swimmers at international events beyond what could be explained in terms of their previous performances (personal bests and international rankings), explaining about 10\% of the residual variance in championship performance.

The theoretical basis for our representation of self-concept comes from the original Shavelson, Hubner and Stanton (1976) theoretical model and subsequent research (e.g., Byrne, 1996; Marsh, Byrne \& Shavelson, 1988; Marsh \& Hattie, 1996) stemming from this classic development. Self-concepts, broadly defined by Shavelson et al., are persons' perceptions of themselves that are formed through experience with and interpretations of their environment, and influenced by evaluations by significant others, reinforcements, and attributions for one's own behavior. An important feature of this model of self-concept is that self-concept is posited to be a multidimensional, hierarchically oriented construct such that global self-esteem or general self-concept appears at the apex of the model and the extent of domain specificity increases as one descends the hierarchy. Within this theoretical framework, selfesteem refers to the global component of self-concept that is specifically intended to reflect broad, 
general self-perceptions that are not specifically tied to particular content areas. This global construct at the top of the hierarchy can be inferred on the basis of higher-order factor analysis or responses to a relatively unidimensional, global self-esteem scale such as the Rosenberg instrument (1965) or selfesteem scales that are part of many multidimensional self-concept instruments (for further discussion, see Marsh, Parada \& Ayotte, 2004).

Because the same person can have a positive self-concept in one domain (e.g., physical) and a negative self-concept in another domain (e.g., academic), a single global measure of self-esteem cannot adequately describe self-concepts in different domains. Therefore, reliance on self-esteem has been criticized as diminishing its power to explain behavior; self-concept researchers argue that self-esteem may not be a particularly useful construct (Marsh, 1993) and emphasize the use of specific components of self-concept most appropriate to a particular setting (Marsh, Parada \& Ayotte, 2004). This concern is particularly relevant in sport/exercise research (Marsh, 2002). Hence, in the present investigation we focused on a specific domain of self-concept, namely the self-concept of one's ability in gymnastics.

Like self-concept in one specific domain, self-efficacy judgments appear near the base of an individual's self-perceptions hierarchy. According to Bandura (1977) self-efficacy refers to "beliefs in one's capabilities to organize and execute the courses of action required to produce given attainments" (p. 3). Whereas self-concept represents one's general perceptions of the self in given domains of functioning, self-efficacy represents individuals' expectations and convictions of what they can accomplish in given situations. Self-efficacy and self-concept are likely to differ in the influence of social comparison and frame of reference effects like those that are the focus of the present investigation (Bong \& Skaalvik, 2003; Marsh, 1993). Frame of reference effects are directly implicated in selfconcept measures as individuals use the performances of other classmates to establish frames of reference for evaluating their own performances, whereas little emphasis is placed on the criteria, standards, or frames of reference that participants use to evaluate the worthiness of their performances in self-efficacy research. Bandura (1986), for example, noted that self-esteem and self-concept—but not self-efficacy - are partly determined by "how well one's behavior matches personal standards of worthiness" (p. 410).

\section{Frame of Reference and the Big-Fish-Little-Pond Effect (BFLPE)}


Self-concept research emphasizes that self-concept cannot be adequately understood if the role of frames of reference is ignored. The same objective characteristics and accomplishments can lead to disparate self-concepts depending on the frames of reference or standards of comparison that individuals use to evaluate themselves. Psychologists from the time of William James (1890) have recognized that objective accomplishments are evaluated in relation to frames of reference. Thus James indicated, "we have the paradox of a man shamed to death because he is only the second pugilist or the second oarsman in the world" (1890, p. 310).

In an educational context, Marsh (1984; Marsh \& Craven, 2002; Marsh \& Parker, 1984) proposed a frame of reference model called the big-fish-little-pond effect (BFLPE) to encapsulate frame of reference effects posited in social comparison theory (Festinger, 1954; Diener \& Fujita, 1997). In reviews of the BFLPE, Marsh (1993; Marsh \& Craven, 2002) indicated that its theoretical basis was derived from research in psychophysical judgment, social judgement, sociology, social comparison theory, and the theory of relative deprivation. In the BFLPE model, Marsh hypothesized that individuals compare their abilities with the abilities of their classmates and use this social comparison impression as one basis for forming their own self-concept. The BFLPE occurs when equally able students have lower self-concepts when they compare themselves to more able students, and higher self-concepts when they compare themselves with less able students. For example, if an average-ability student is in a class of highly able students, this student's academic abilities would be lower than the average of the other students in this class, and this discrepancy would lead to academic self-concepts that are below average. Conversely, if the student is in a class of less able students, then this student's academic ability would be above the average of the other students in the class, and that difference would lead to academic selfconcepts that are above average. According to the BFLPE model, academic self-concept will be correlated positively with individual achievement (more able students will have a higher self-concept), but negatively related to class-average achievement (the same student will have a lower academic selfconcept when class-average ability is high). The nature of these effects and the path analyses typically used to demonstrate them are illustrated in Figure 1A where we focus on the effects of individual and class-average gymnastics skills on gymnastics self-concepts, the focus of the present investigation. Whereas good individual skills are associated with a positive self-concept (the ++ path leading from 
individual skills to self-concept), the effect of class-average skills on self-concept is negative (the - path leading from class-average skills to self-concept)—being in a class where most other students are better than I am will lower my self-concept.

The BFLPE is posited to be domain specific, supporting the multidimensional perspective of self-concept rather than a unidimensional approach that focuses exclusively on global self-concept or self-esteem. The BFLPE in traditional academic settings-the negative effect of school-average or classaverage achievement measures—is specific to academic self-concept. Marsh and Parker (1984; Marsh, 1987) showed that there were large negative BFLPEs for academic self-concept, but little or no BFLPEs on general self-concept or self-esteem. Marsh, Chessor, Craven and Roche (1995) reported two studies of the effects of participation in gifted and talented academic programs on different components of selfconcept over time and in relation to a matched comparison group. There was clear evidence for negative BFLPEs in that academic self-concept in the gifted and talented programs declined over time and in relation to control groups, but effects were small or non-significant for non-academic components of self-concept and global self-esteem. Demonstrating the generalizability of the results, Marsh (1991, 1994) reported that the effects of school-average achievement on academic self-concept were negative in two very large US studies, each based on nationally representative samples of more than 1,000 US high schools.

Support for the cross-cultural generalizability of the BFLPE comes from studies from other countries. Marsh, Koller, and Baumert (2001) compared the size of the negative BFLPE on the academic self-concepts of East and West German students following the fall of the Berlin Wall. Prior to the reunification, West German students had attended segregated schools largely based on their academic ability whereas East German students attended unsegregated schools in which there were mixed ability levels. They found that when "selective schooling" was first introduced in East Germany with the reunification of the East and West German school systems, the BFLPE for East German students at the start of the school year was not nearly as large as for West German students (who had already been in ability grouped schools for the two previous years). The size of the BFLPE was larger for East German students by the middle of the school year, and did not differ from the West German schools by the end of the first school year following the reunification. This suggests that the BFLPE does not occur 
immediately, but takes some time to take effect.More recently, Marsh and Hau (2003; Marsh, Hau \& Craven, 2004) presented results from a large cross-cultural study (conducted by the Organisation for Economic Cooperation and Development) consisting of nationally representative samples of approximately 4,000 15-year olds from each of 26 countries (total $N=103,558)$, who completed the same self-concept instrument and achievement tests. The effects of school-average achievement on academic self-concept were negative in all 26 countries and, consistent with previous research, the size of the BFLPE did not vary with the students' initial ability levels. Taken together, the research evidence suggests that the BFLPE is very robust, with broad generalizability across educational settings.

\section{Translating the Big-Fish-Little-Pond Effect (BFLPE) into Sport/Exercise Settings}

In sport/exercise psychology there is growing support for the importance of physical selfconcept both as an outcome variable and as a mediating variable that facilitates the attainment of other desirable outcomes (Fox, 1997; Marsh, 2002). Considering this importance, some studies have tried to determine what sources of information individuals use to judge their competence in this context (for a review see Horn, 2004). Horn and Weiss (1991) developed the Physical Competence Information Scale (PCIS), a self-report questionnaire used in several studies to assess the importance of 11 informational criteria presented (e.g., peer comparison, peer evaluation, skill improvement, effort exerted in practices and games) in helping individuals to know how good they were at sport/exercise. Although the particular sources of information vary somewhat as a function of particular studies, there is general agreement that dependency on parental informational feedback and game outcome by young children (under 10 years) decreased, whereas peer comparison and social comparison increased for older respondents. Although these studies showed that social comparison was a salient source of information used by the adolescents to elaborate their sport self-concept, to our knowledge no sport/exercise study has specifically examined the type of frame of reference effect posited in the BFLPE.

In related research, Marsh (1993) demonstrated frame of reference effects associated with gender and age affected relations between physical self-concept and a comprehensive battery of physical fitness indicators (e.g., cardiovascular endurance, power, dynamic strength, static strength, flexibility, body composition). For example, whereas performance on a 1.6 kilometre run was related to physical self-concept for boys and girls across different ages, the relation was more accurately represented by 
controlling the effects of gender and age. Thus, even though the running speed of a 9-year-old girl might be very slow relative to those of 15 -year-old boys (and the total sample), her running speed was positively correlated with physical self-concept if it was fast relative to other 9-year-old girls. Hence, the frame of reference used to form self-evaluations of running speed was based in part on social comparisons with other children of a similar age and gender. Although these frame of reference effects associated with gender and age are clearly different from those posited in the BFLPE, in each case the predictions are that individuals use the performances of other individuals in their immediate context as one basis for evaluating their own performances.

\section{The Present Investigation}

We know of no previous research evaluating the generalizability of the BFLPE to physical selfconcept and performances in a physical domain. Whereas the extension of the BFLPE to a sport psychology setting has important implications for the evaluation of the generalizability of the BFLPE beyond the traditional academic setting in which it has been tested, it also opens up a new area of research in sport/exercise psychology that has important theoretical, substantive and practical applications for sport psychologists, physical education teachers, physical fitness trainers, and coaches. Hence, the overarching purpose of the present investigation is to evaluate BFLPEs in relation to gymnastics self-concepts of adolescents who participate in a gymnastics-training program. In the present investigation, French students completed a performance-based test of gymnastic skills and a gymnastics self-concept measure at the start of the program (T1), and at the end of the program (T2) students again completed the gymnastics self-concept measure. Consistent with BFLPE in traditional academic settings reviewed earlier, we tested the following a priori predictions and research questions (also see Figure 1A and 1B).

1. The effect of individual gymnastics skill on gymnastics self-concept is predicted to be positive (the ++ path leading from individual gymnastics skills to gymnastics self-concept in Figure 1A). When T2 self-concept is added to the path model (Figure 1B), the total effect of individual gymnastics skill is predicted to be positive for both T1 and T2 self-concepts, although much of the effect of individual skill on T2 self-concept is expected to be mediated by T1 self-concept. Because gymnastics is a traditional component of physical education in the French system, all of these students would have had previous 
gymnastics experience — both formally and informally — that would provide a basis for reasonably accurate self-evaluations of their own gymnastics skills prior to the start of this study. However, because participation in the class provides a basis for students to form more accurate perceptions of their gymnastics skills, we predict that the effect of individual gymnastics skills on T2 gymnastics selfconcept will be positive even after controlling for T1 gymnastics self-concept (i.e., the path relating individual skills to T2 self-concept when T1 self-concept is also included in the model—see Figure 1B).

2. The effect of class-average gymnastics skill on gymnastics self-concept is predicted to be negative (the - path leading from individual gymnastics skills to gymnastics self-concept in Figure 1A; the BFLPE). When T2 self-concept is added to the path model (Figure 1B), the total effect of classaverage gymnastics skill is predicted to be negative for both $\mathrm{T} 1$ and T2 self-concepts, although much of the negative effect of class-average skills on T2 self-concept is expected to be mediated by T1 selfconcept. Because the gymnastics component of the physical education class was conducted in the second half of the school year, students would have had ample time to get to know the general physical and movement skills of their classmates that are related to gymnastics performance. Furthermore, many of the students would have been in previous classes with many of the same students where there was a gymnastics component. Thus, students would have a reasonable idea of how their physical skills relevant to gymnastics compared with those of other students at the start of the gymnastics component. However, because the BFLPE is a gradual effect that increases over time (e.g., Marsh, Koller, \& Baumert, 2000), we predict that there will be a direct effect of class-average skills on T2 self-concept (i.e., the path leading from class-average skills to T2 self-concept in Figure 1B) as well as the substantial effect that is mediated through T1 self-concept. Equivalently, this prediction can be expressed as indicating that the effect of class-average gymnastics skills will be significantly negative for T2 gymnastics self-concept even after controlling for the effects of class-average skills on T1 gymnastics self-concepts.

3. To what extent does the BFLPE (the negative effect of school-average achievement) vary as a function of gender, age, and individual levels of gymnastic skill? In order to evaluate this research question, we tested interactions between the class-average gymnastics skill (the BFLPE) and individual (a) gender, (b) age, and (c) gymnastics skill levels. Previous research in academic settings suggests that 
these interaction effects will be small or non-significant, although this may not be a particularly good basis for offering a priori predictions for this application in a physical activity domain. We note, however, that tests of these interactions have important implications for theory, research, and practice. In particular, previous research has found that students of all ability levels-even students near the top of their class in selective academic settings and not just those at the bottom of their class - experience the negative effects of the BFLPE on self-concept.

\section{Method}

\section{Participants and Procedures}

Participants were 430 French students (52\% boys) from 20 seventh, eighth or ninth grade classes in 6 French Junior High Schools situated in predominantly middle class areas in the south of France. In France, physical education is a compulsory subject for all high school students. Generally, physical education teachers teach each of several physical and sporting activities in 10-week cycles. The study was conducted during gymnastics cycles in scheduled physical education lessons. Data were collected twice, at the first class period (T1) and at the end of the gymnastics cycle (T2). Self-concept, gender, age, and gymnastics skills were assessed by the first author and two assistants using a questionnaire and a standardized test (see below) at T1, and the questionnaire was then completed again by students at the end of the program (T2). The anonymity of the responses was guaranteed and it was emphasized to students that there were no right or wrong responses and that each student should answer honestly. Students' initial gymnastic skills were assessed by videotaping each student on a gymnastics skills test that they completed three times during a class session prior to the start of the gymnastics component of the class (thus ensuring that initial skill levels were not confounded with gains associated with the class). In order to ensure anonymity of responses, students were only identified in terms of class, gender and date of birth. However, because T1 and T2 responses by some students could not be matched on these variables (due to missing or inaccurate demographic information), the final sample was reduced to 405 students, 210 boys and 195 girls ( $M$ age $=13.5$ years $)$.

\section{Measures}

Students' gymnastics skills were based on a gymnastics performance test consisting of basic performance exercises. Three judges expert in gymnastics rated the videotaped performance of each 
student on a 1 (low level) to 7 (high level) response scale. The test consisted of five gymnastic exercises (e.g., stretched handstand back drop, backward roll, cartwheel). Each judge made a single global rating of the student after viewing the student's performance on all five exercises. As students completed the set of exercises three times, each judge appraised each student three times and the highest rating was used in subsequent analyses. Based on responses by the three different raters, inter-judge reliability was very good $(\alpha=.93)$. The mean of the three judge's scores was calculated and used as an indication of students' initial gymnastics skills.

Students' T1 and T2 gymnastics self-concepts were assessed with a 3-item scale adapted from previous research by Nicholls (e.g., Duda \& Nicholls, 1992; Nicholls, Cheung, Lauer, \& Patashnick, 1989) and Eccles (e.g., From \& Eccles, 1998): (a) "How good do you think you are in gymnastics", (b) "For me, gymnastics is" and (c) "Compared to your classmates how good do you think you are in gymnastics". Response options for the three items ranged from: (a) not good at all to very good, (b) very difficult to very easy, (c) the worst to the best, respectively. The students' responses for each item were scored on a 7-point scale, with higher scores reflecting more positive self-perceptions. In previous research this questionnaire had shown good construct validity, internal consistency, and predictive validity (e.g., Sarrazin, Roberts, Cury, Biddle, \& Famose, 2002). In the present investigation, there is support for construct validity of responses to this scale in that responses were internally consistent $(\alpha=$ .82 at $\mathrm{T} 1, .87$ at $\mathrm{T} 2)$, reasonably stable over time $(r=.77)$, and substantially related to actual gymnastics performance $(r=.48)$.

\section{Statistical Analysis}

In pursuing tests of the a priori predictions and research questions, we applied multilevel modeling - a statistical methodology specifically designed to evaluate multilevel data. This allowed us to partition variance associated with different effects into components associated with the individual student (Level 1) and the class (Level 2) and provided appropriate statistical tests for the effects of school-average gymnastics skills. In the present investigation, multilevel analyses conducted with MLWin (Rasbash, Browne, Healy, Cameron \& Charlton, 2001) were used to relate individual gymnastic skills, class-average gymnastics skills, gender, and age to gymnastics self-concept. In order to evaluate the size, nature, and statistical significance of the interaction between individual gymnastics skills and 
class-average gymnastics skills, cross-product terms reflecting these variables were also included in the analyses. Hence, individual student self-concept was the main outcome (dependent) variable, whereas predictor variables were individual student gymnastics skills and class-average gymnastics skills. Also considered were the interactions between class-average gymnastics skills and gender, age, and individual gymnastics skills.

We began by standardizing (z-scoring) all individual level variables to have $M=0, S D=1$ across the entire sample (see Marsh \& Rowe, 1996; also see Raudenbush \& Bryk, 2002). Class-average measures of gymnastics skills were determined by taking the average of gymnastics skills scores for participants in each class (but not re-standardizing these scores so that individual and class-average gymnastics skills scores were in the same metric). Product terms were used to test interactions. In constructing these product variables, we used the product of individual (z-score) standardized variables (but the product terms were not re-standardized).

Consistent with the multilevel design of the study, we tested our longitudinal path model using a twolevel multilevel multiple regression model in which participants (Level 1) were nested within classes (Level 2). In general, it is inappropriate to pool responses of individual participants without regard to class unless it can be shown that classes do not differ significantly from each other. If, for example, there are systematic differences between classes, then the typical single-level analyses (e.g., univariate and multivariate ANOVAs, multiple regression, structural equation models) that ignore this clustering of participants into classes are likely to be invalid (violating statistical assumptions in a way that increases the likelihood of finding a significant effect where there is none). Furthermore, characteristics associated with individual participants are likely to be confounded with those based on classes. Multilevel analyses are particularly relevant when an important focus of the study is on a class-level attribute (e.g., classaverage gymnastics skills) and interactions between class-level and individual student-level attributes (e.g., interaction between class-average and individual student levels of gymnastics skills).

From a practical perspective, a systematic multilevel approach allows researchers to pursue new questions about how effects vary from class to class. This is particularly important in studies such as the present investigation in which critical variables are associated with both the individual participant level (gymnastics self-concept and gymnastics skills) and the class level (class-average gymnastics skills). In 
the present investigation, for example, the use of a multilevel approach allows us to determine the extent to which the observed pattern of relations between gymnastics self-concept and gymnastics skills generalizes from class to class and, of particular relevance, to test appropriately the effects of variables from one level on variables from another level and to test cross-level interactions between variables from different levels. Hence, the multilevel approach provides a much richer and more appropriate approach to testing our theoretical predictions than would be possible with traditional single-level approaches that ignore the fact that students are clustered within classes (Goldstein, 2003; Raudenbush \& Bryk, 2002).

\section{Results}

\section{Preliminary Results: The Effects of Gender and Age}

Are there systematic age and gender effects in either gymnastics skills or gymnastics selfconcepts? Although not directly relevant to tests of a priori hypotheses, an evaluation of the effects of gender, age and their interaction is interesting and facilitates interpretations of these effects in subsequent analyses. For gymnastics skills, there are (a) an effect for gender, with girls scoring higher than boys, (b) a positive effect of age (older participants have better skills), and (c) a non-significant gender $\times$ age interaction effect. Whereas boys typically have higher scores in many physical skills, girls in the present investigation have modestly better gymnastics skills than boys. Also, gymnastics skills improve with age during this early adolescent period.

\section{Insert Table 1 about Here}

For T1 gymnastics self-concept, the only significant effect is for gender. Interestingly, boys have slightly higher self-concepts than girls even though their actual skill levels are somewhat poorer than those of girls. This suggests that boys, relative to girls, begin with a slight positive bias in their gymnastics self-concepts - at least in relation to their actual skill levels. By T2, however, there are no significant differences between the self-concept levels of boy and girls. Reflecting this difference between $\mathrm{T} 1$ and $\mathrm{T} 2$ results, Model 2C (T2 self-concept controlling for T1 self-concept) shows that girls have slightly higher self-concept scores. That is, the change in the relative ranking of students in terms of self-concept is more positive for girls than for boys. In Model 2C there is also a very small positive effect of age, indicating that change in self-concept over time is slightly more positive for older participants. 


\section{The BFLPE on Gymnastics Self-concept}

T1 Gymnastics Self-concept (Model 3A). Is there a BFLPE for T1 gymnastics self-concept? The most important results for Model 3A (see Table 2) are the effects of individual and class-average gymnastics skills on T1 gymnastics self-concept. Consistent with Prediction 1, the effect of individual gymnastics skills is substantial and positive (.59). Of particular importance and consistent with Prediction 2, the effect of class-average gymnastics (the BFLPE) is substantial and negative (-.46). Hence, these results demonstrate that the BFLPE that is so robust in academic settings also generalizes to a physical setting.

\section{Insert Table 2 about Here}

T2 and $\Delta T 2$ Gymnastics Self-concept (Model 3B). Is there a BFLPE for T2 gymnastics selfconcept? The results for T2 gymnastic self-concept (Mode1 3B) largely mirror those based on T1 selfconcept. It is interesting to note, however, that the effects of individual gymnastics skills (.61) and particularly class-average gymnastics skills (-.68) are larger at T2 than T1. Reflecting this difference, (Model 3C; T2 self-concept, controlling for T1 self-concept), the effects of individual skills and classaverage skills are both statistically significant. Hence, consistent with predictions, the effect of $\mathrm{T} 1$ gymnastics skills has an additional direct effect on T2 gymnastics self-concepts (.18) beyond the substantial indirect effect that is mediated through $\mathrm{T} 1$ self-concepts. Of particular importance and also consistent with a priori predictions, there is a direct negative effect (-.35) on class-average skills on T2 self-concept (the BFLPE) beyond the negative effects of class-average achievement already experienced at T1. Hence, the positive effect of individual skills and the negative effects of class-average skills grow larger over time- - beyond the substantial effects that are mediated through T1 self-concept.

\section{The Generality of the BFLPE: Interactions with Gender, Age, and Individual Skill Levels.}

To what extent does the size of the BFLPE vary as a function of gender, age, and individual skill level? To answer these questions, we added interaction terms to models already considered (see Models 4A, 4B, and 4C in Table 3). The results of these complicated multilevel models are easy to summarize. In none of the three models were any of the interaction effects statistically significant. We explored this result further by considering each of the interactions effects separately instead of simultaneously, but each of the interaction effects was still non-significant. Hence, there was no evidence that the size of the 
negative effect of class-average gymnastics skills (the BFLPE) varied systematically as function of age, gender, or initial gymnastic skill levels.

\section{Insert Table 3 about Here}

\section{Discussion}

The present investigation is apparently the first to demonstrate clear support for the BFLPE in a physical activity setting. Whereas there is growing support for the negative effect of class-average academic achievement on academic self-concept, ours is apparently the first to test for this effect in relation to a physical activity and a physical component of self-concept. The successful demonstration of the BFLPE in a physical domain has important theoretical implications for the study of self-concept, but also has important practical implications for sport/exercise researchers and practitioners.

\section{Implications for theory, research and practice}

Theoretically, it is important to show that an effect that is so robust in relation to the academic domain of self-concept also generalizes so well to a physical domain. Based on their large cross-cultural study of nationally representative samples from 26 countries, Marsh and Hau (2003) concluded that "the BFLPE may approach what Segall, Lonner, and Berry (1998, p. 1102) refer to as a 'nearly universal psychology, one that has pan-human validity'-one of the goals of cross-cultural research." To this impressive support for the generality of support across diverse groups of individuals from different countries, the present investigation adds support for the generality of support across different domains. Whereas it is clearly too early to speculate about the generality of the BFLPE across different sport and exercise settings, the results based on diverse educational settings suggest that the effect may be broadly generalizable. Because this is apparently the first demonstration of the BFLPE in a physical setting, discussion of practical implications and potential strategies to counter the effects must be highly speculative and draw substantially on results from educational psychology.

The results of the present investigation dictate new research that is needed to test the range of practical implications of the BFLPE in a wide variety of sport and exercise settings. Although physical education classes and gymnastic performances are clearly very different from classes in traditional academic school subjects and results on standardized achievement test scores that have been the basis of previous BFLPE studies, it is important to pursue the results in other sport and physical activity settings 
that are not part of a traditional education setting. The practical implications of the BFLPE are particularly relevant to programs that bring together the best athletes from a particular region, state or country into a single institution for purposes of training. Whereas there may be important economies of scale and other advantages in this practice, the BFLPE suggests that the physical self-concepts of these athletes might suffer (for further discussion, see Marsh, 2002; Marsh, Kong \& Hau, 2000). Indeed, whereas there may be important advantages for training in such selective settings (e.g., opportunities to model and learn from other top performers, material advantages for performers and coaches), accumulative results from educational settings suggest that this practice is likely to be negative in terms of self-concept (Marsh \& Hau, 2003). Again drawing on research particularly in educational settings, there is good support for a reciprocal effects model of self-concept and performance whereby prior selfconcept has an effect on subsequent performance beyond the effect of prior performance, and prior performance has an effect on subsequent self-concept beyond the effect of prior self-concept. According to this research, self-concept and performance are mutually reinforcing constructs so that each will be undermined if either is ignored.

Because there is little or no BFLPE research based on elite athletes from which to draw, we developed some hypothetical scenarios from elite swimming in order to explore possible implications of the BFLPE. Imagine a top-ranked swimming team that contains three of the top five swimmers in the world in the 1500 metre event. The third best swimmer in this group of three is an outstanding swimmer in terms of objective swimming performances, but may suffer an elite-athlete version of the BFLPE. His outstanding accomplishments are likely to be overshadowed by those of the other two swimmers. He will not even be able to represent his country in the Olympics in this event, as each country is only able to send two representatives in a given event. To the extent that this swimmer evaluates his performances relative to those of his teammates, this third best swimmer will suffer a relatively poor elite swimmer self-concept (relative to his outstanding accomplishments) that may have negative implications for his future accomplishments. Now imagine an equally competent 1500 metre swimmer from another country that has a modest swimming program, with no other swimmers in the top five in any events. To the extent to which this swimmer evaluates his accomplishments relative to those of his teammates, he will 
have a relatively good elite swimming self-concept that is likely to have positive implications for his future accomplishments.

Marsh (1993, Marsh \& Craven, 1997; 2002) argued on the basis of academic self-concept research that some individual participants may be more immune to the BFLPE than others and that there may be strategies to counter the BFLPE. Translating some of these suggestions into a physical setting provides potential strategies that might be useful as well for sport psychology practitioners:

1. Expanding the basis for selecting participants to include criteria other than standardized performance measures. Whereas participants of all ability levels are influenced by the BFLPE, it may be that highly independent participants who gain satisfaction from individual improvement, achieving personal bests, and mastery of new skills, are less likely to be negatively affected by the BFLPE than participants who gain satisfaction from competing with and "beating" other participants and from being the "best" participant in their class.

2. Developing assessment tasks that encourage individual participants to pursue their own goals that are of particular interest to themselves, to reduce social comparison. To the extent that participants pursue their own unique goals (e.g., attainment of personal best performances) and feel positive about the results, they should be able to maintain a positive self-concept even if other participants in selective settings are "more able" according to traditional performance measures.

3. Avoiding a highly competitive environment that encourages the social comparison processes underlying the BFLPE. Ironically, it seems that some selective programs intentionally foster a highly competitive environment that is likely to exacerbate the BFLPE rather than to counteract it.

4. Providing participants with feedback in relation to criterion reference standards and personal improvement over time rather than comparisons based on the performances of other participants. To the extent that feedback emphasizes how each participant compares with other participants in the same setting, the BFLPE is likely to be exacerbated.

5. Emphasizing to each participant that she or he is a very able participant and valuing the unique accomplishments of each individual participant so that all participants can feel good about themselves. 
6. Enhancing participants' feelings of connection, bonding, or identification with other participants in the selective setting and the group as a whole so that they develop a positive perspective from being associated with an elite group of participants (see discussion of reflected glory effect by Marsh, Kong \& Hau, 2000)

Although clearly beyond the scope of the present investigation, we suggest that a particularly useful direction for further research is to consider the motivational orientations of individuals and the motivation climates associated with particular settings. Some support for these speculations comes from the Marsh and Peart (1988) study in which a competitively oriented acrobics intervention that emphasized social comparison led to a decline in physical self-concept (relative to those in a randomly assigned control groups) even though physical fitness levels increased. In contrast, in a cooperatively oriented group where exercises were done in pairs and emphasis was placed on personal improvement over time, there was an increase in both physical fitness levels and physical self-concept. The authors speculated that in terms of maintaining long-term physical activity levels, the effects on physical selfconcept might be more important than the short-term effects on physical fitness resulting from the intervention. Whereas classroom climate is inherently a class-level variable, recent applications of multilevel modeling (e.g., Papaioannou, Marsh, \& Theodorakis, 2004) provide examples of how to appropriately disentangle the effects of individual motivation orientation and classroom climate in the physical domain.

\section{Limitations and directions for future research.}

In the present investigation, results were available for 20 classes and 405 students. Whereas this sample size is large relative to many sport/exercise psychology studies, it is small relative to multilevel studies. Simulation research (e.g., Raudenbush \& Liu, 2000; also see Marsh \& Hau, 2003; Marsh, Kong \& Hau, 2000; Papaioannou, et al., 2004) suggests that the number of classes needed depends, to some extent, on the number of students in each class and the particular question that is asked. However, like most questions about sample size, the general answer is that "more is better" (Marsh, Hau, Balla, \& Grayson, 1998). Particularly in research where the specific interest is in class characteristics (e.g., classaverage gymnastic skills), it is necessary that there are a large number of classes. However, 20 classes included in the present investigation are probably a realistic minimum and a larger number of classes 
would be desirable - particularly if researchers are interested in exploring other student and class characteristics that moderate the size of the BFLPE. In the present investigation, we were not particularly successful in finding moderating variables. Whereas these findings support the generalizability of the BFLPE in the physical domain in that the size of the effect did not vary significantly with (i.e., interact with) gender, age, and initial skill levels, the relatively small number of classes meant that the statistical power of tests of interactions involving class-level variables (i.e., classaverage skill levels - the BFLPE) was limited. Nevertheless, even research in educational settings based on much larger sample sizes (classes and individuals) has not been particularly successful in discovering moderating variables.

\section{Conclusion}

In the present investigation, we demonstrated the BFLPE in a sport/exercise setting whereby gymnastics self-concept is positively predicted by an individual's own gymnastic skills but negatively predicted by the average level of skills of other participants in the same gymnastics class. Although there is impressive support for the generality of the negative effect of the BFLPE on academic selfconcept in academic settings, this is apparently the first demonstration of the effect in a sport/exercise setting. 


\section{References}

Bandura, A. (1977). Social learning theory. Prentice-Hall: Englewood Cliffs, NJ.

Bandura, A. (1986). Social foundations of thought and action: A social cognitive theory. Englewood Cliffs, NJ: Prentice-Hall.

Bong, M., \& Skaalvik, E. M. (2003). Academic Self-concept and self-efficacy: How different are they really. Educational Psychology Review, 15, 1-40.

Branden, N. (1994). Six pillars of self-esteem. New York: Bantam.

Brustad, R. J. (1988). Affective outcomes in competitive youth sport: The influence of intrapersonal and socialization factors. Journal of Sport \& Exercise Psychology, 10, 307-321.

Byrne, B. (1996). Measuring self-concept across the life span: Issues and instmumentation. Washington, DC: American Psychological Association.

Diener, E. \& Fujita, F. (1997). Social comparison and subjective well-being. In B. P. Buunk, \& F. X. Gibbons (Eds). Health, coping, and well-being: Perspectives from social comparison theory (pp. 329-358). Mahwah, NJ: Erlbaum .

Duda, J. L., \& Nicholls, J. G. (1992). Dimensions of achievement motivation in schoolwork and sport. Journal of Educational Psychology, 84, 1-10.

Fox, K. R. (1997). The physical self: From motivation to well-being. Champaign, IL : Human Kinetics.

From, P.M., \& Eccles, J.S. (1998). Parents' influence on children's achievement-related perceptions. Journal of Personality and Social Psychology, 74, 435-452.

Goldstein, H. (2003). Multilevel Statistical Models ( $3^{\text {rd }}$ ed.). London: Hodder Arnold.

Horn, T. S. (2004). Lifespan development in sport and exercise psychology: Theoretical perspectives. In M. Weiss (Ed.), Developmental sport and exercise psychology: A lifespan perspective (pp. 27-71). Morgantown,WV: Fitness Information Technology.

Horn, T. S., \& Weiss, M. R. (1991). A developmental analysis of children's self-ability judgments in the physical domain. Pediatric Exercise Science, 3, 310-326.

James, W. (1890/1963). The principles of psychology. New York: Holt, Rinehart \& Winston.

Marsh, H. W. (1984). Self-concept: The application of a frame of reference model to explain paradoxical results. Australian Journal of Education, 28, 165-181. 
Marsh, H. W. (1987). The-big-fish-little-pond effect on academic self-concept. Journal of Educational Psychology, 79, 280-295.

Marsh, H. W. (1993). Physical fitness self-concept: Relations to field and technical indicators of physical fitness for boys and girls aged 9-15. Journal of Sport and Exercise Psychology, 15, 184-206.

Marsh, H. W. (1994). Using the National Educational Longitudinal Study of 1988 to evaluate theoretical models of self-concept: The Self-Description Questionnaire. Journal of Educational Psychology, 86, $439-456$.

Marsh, H. W. (2002). A multidimensional physical self-concept: A construct validity approach to theory, measurement, and research. Psychology: Journal of the Hellenic Psychological Society, 9, 459-493.

Marsh, H. W., Byrne, B. M., \& Shavelson, R. (1988). A multifaceted academic self-concept: Its hierarchical structure and its relation to academic achievement. Journal of Educational Psychology, $80,366-380$.

Marsh, H. W., Chessor, D., Craven, R. G., \& Roche, L. (1995). The effects of gifted and talented programs on academic self-concept: The big fish strikes again. American Educational Research Journal, 32, 285-319.

Marsh, H. W., \& Craven, R. (1997). Academic Self-concept. Beyond the dustbowl. In G. D. Phye (Ed.), Handbook of Classroom assessment (pp. 131-198). San Diego, CA: Academic Press.

Marsh, H. W., \& Craven, R. (2002). The pivotal role of frames of reference in academic self-concept: The "big-fish-little-pond" effect. In F. Pajares \& T. Urdan (Eds.), Adolescence and Education (Volume II, pp. 83-123). Information Age Publishing Inc.

Marsh, H. W., \& Hattie, J. (1996). Theoretical perspectives on the structure of self-concept. In B.A. Bracken (Ed.), Handbook of self-concept (pp. 38-90). New York: Wiley.

Marsh, H. W. \& Hau, K. T. (2003). Big fish little pond effect on academic self-concept: A cross-cultural (26 country) test of the negative effects of academically selective schools. American Psychologist, $58,1-13$

Marsh, H. W., Hau, K-T., Balla, J R., \& Grayson, D. (1998) Is more ever too much? The number of indicators per factor in confirmatory factor analysis. Multivariate Behavioral Research, 33, 181-220. 
Marsh, H. W., Hau, K., \& Craven, R. (2004). The Big-Fish-Little-Pond Effect Stands Up to Scrutiny. American Psychologist, 59, 269-271.

Marsh, H. W., Koller, O., \& Baumert, J. (2001). Reunification of East and West German school systems: Longitudinal multilevel modeling study of the big fish little pond effect on academic selfconcept. American Educational Research Journal, 38, 321-350.

Marsh, H. W., Kong, C. K., \& Hau, K. T. (2000). Longitudinal multilevel modeling of the big fish little pond effect on academic self-concept: Counterbalancing social comparison and reflected glory effects in Hong Kong high schools. Journal of Personality and Social Psychology, 78, 337-349.

Marsh, H. W., Parada, R. H. \& Ayotte, V. (2004). A multidimensional perspective of relations between self-concept (Self Description Questionnaire II) and adolescent mental health (Youth Self Report). Psychological Assessment, 16, 27-41.

Marsh, H. W. \& Parker, J. (1984). Determinants of student self-concept: Is it better to be a relatively large fish in a small pond even if you don't learn to swim as well? Journal of Personality and Social Psychology, 47, 213-231.

Marsh, H. W. \& Peart, N. (1988). Competitive and cooperative physical fitness training programs for girls: Effects on physical fitness and on multidimensional self-concepts. Journal of Sport and Exercise Psychology, 10, 390-407.

Marsh, H. W., \& Rowe, K. J. (1996). The negative effects of school average ability on academic selfconcept - An application of multilevel modelling. Australian Journal of Education, 40, 65-87.

Nicholls, J. G., Cheung, P., Lauer, J., \& Patashnick, M. (1989). Individual differences in academic motivation: Perceived ability, goals, beliefs, and values. Learning and Individual Differences, 1, 63-84.

Papaioannou, A., Marsh, H.W., Theodorakis, Y. (2004). A Multilevel Approach to Motivational Climate in Physical Education and Sport Settings: An Individual or a Group Level Construct. Journal of Sport and Exercise Psychology, 26, 90-118.

Rasbash, J., Browne, W., Healy, M., Cameron, B. \& Charlton, C. (2001). MLWin Software 1.1.

Raudenbush, S. W. \& Bryk, A. S. (2002). Hierarchical linear models: Applications and data analysis methods ( $\left.2^{\text {nd }} e d.\right)$. Thousand Oaks, CA: Sage. 
Raudenbush, S. W., \& Liu, X. (2000). Statistical power and optimal design for multisite randomized trials. Psychological Methods, 5, 199-213.

Rosenberg, M. (1965). Society and the adolescent child. Princeton: Princeton University Press.

Sarrazin, P., Roberts, G., Cury, F., Biddle, S., \& Famose, J. P. (2002). Exerted effort and performance in climbing among boys: The influence of achievement goals, perceived ability, and task difficulty. Research Quarterly for Exercise and Sport, 73, 425-436.

Scanlan, T. K., \& Simmons, J. P. (1992). The construct of sport enjoyment. In G. C. Roberts (Ed.), Motivation in sport and exercise (pp. 199-215). Champaign, IL: Human Kinetics.

Scanlan, T. K., Stein, G. L., \& Ravizza, K. (1991). An in-depth study of former elite figure skaters: III. Sources of stress. Journal of Sport \& Exercise Psychology, 13, 103-120.

Segall, M. H., Lonner, W. J., \& Berry, J. W. (1998). Cross-cultural psychology as a scholarly discipline: On the flowering of culture in behavioral research. American Psychologist, 53, 1101-1110.

Shavelson, R. J., Hubner, J. J., \& Stanton, G. C. (1976). Self-concept: Validation of construct interpretations. Review of Educational Research, 46, 407-441.

Weigand, D. A. \& Broadhurst, C. J. (1998). The relationship among perceived competence, intrinsic motivation, and control perceptions in youth soccer. International Journal of Sport Psychology, 29, $324-338$.

Weiss, M. R., \& Ebbeck, V. (1996). Self-esteem and perceptions of competence in youth sport: Theory, research, and enhancement strategies. In O. Bar-Or (Ed.), The encyclopedia of sports medicine, Vol. VI: The child and adolescent athlete (pp. 364-382). Oxford: Blackwell Scientific Publications.

Weiss, M. R., \& Ferrer-Caja, E. (2002). Motivational orientations and sport behavior. In T. Horn (Ed.), Advances in sport psychology (2nd ed.) (pp. 101-184). Champaign, IL: Human Kinetics.

Weiss, M.R., \& Horn. T.S. (1990). The relation between children's accuracy estimates of their physical competence and achievement-related characteristics. Research Quarterly for Exercise and Sport, 61, $250-258$

Weiss, M. R., McAuley, E., Ebbeck, V. \& Wiese, D. M. (1990). Self-esteem and causal attributions for children's physical and social competence in sport. Journal of Sport \& Exercise Psychology, 12, 21-36. 


\section{Table 1}

Gymnastic Skills and Gymnastics Self-concept: Effects of Gender and Age.

\begin{tabular}{|c|c|c|c|c|c|c|c|c|}
\hline \multirow[b]{2}{*}{ Variables } & \multicolumn{2}{|c|}{$\begin{array}{c}\text { Model } 1 \\
\text { Gym skill }\end{array}$} & \multicolumn{2}{|c|}{$\begin{array}{c}\text { Model 2A } \\
\text { T1Gym SC }\end{array}$} & \multicolumn{2}{|c|}{$\begin{array}{c}\text { Model 2B } \\
\text { T2Gym SC }\end{array}$} & \multicolumn{2}{|c|}{$\begin{array}{c}\text { Model 2C } \\
\Delta \text { T2Gym } \\
\text { SC }\end{array}$} \\
\hline & Effect & $\mathrm{SE}$ & Effect & $\overline{\mathrm{SE}}$ & Effect & SE & Effect & $\mathrm{SE}$ \\
\hline \multicolumn{9}{|l|}{ Fixed effect } \\
\hline Gender & $-.20 *$ & .05 & $.17^{*}$ & .05 & .08 & .05 & $-.06^{*}$ & .03 \\
\hline Age & $.19^{*}$ & .06 & -.02 & .06 & .05 & .06 & $.08^{*}$ & .03 \\
\hline Age $\times$ Gender & -.02 & .05 & .04 & .05 & .06 & .05 & .03 & .03 \\
\hline T1 Gym SC & & & & & & & $.81^{*}$ & .03 \\
\hline Constant & .01 & .07 & .00 & .07 & .01 & .06 & .01 & .06 \\
\hline \multicolumn{9}{|l|}{ Residual Variance components } \\
\hline Level 2 Class & .05 & .03 & .04 & .03 & .02 & .02 & .01 & .01 \\
\hline Level 1 Students & $.86^{*}$ & .06 & $.94 *$ & .07 & $.96^{*}$ & .07 & $.34 *$ & .03 \\
\hline
\end{tabular}

Note. All outcome and predictor variables were standardized $(M=0, S D=1)$ so that effects correspond to standardized beta weights. Gym Skill = Objective measures of gymnastic skills; T1Gym SC and T2Gym SC = Gymnastic self-concept measured at the start and end of the program; $\Delta \mathrm{T} 2 \mathrm{Gym} \mathrm{SC}=\mathrm{T} 2$ self-concept controlling for the effect of T1 self-concept. All parameter estimates are statistically significant when they differ from zero by more than two standard errors (SEs). Analyses are based on responses by 405 students from 20 classes. 
Table 2

Big Fish-Little-Pond Effect (BFLPE): The Effect of Class-Average Gymnastics Skill on Gymnastics Self-concept.

\begin{tabular}{|c|c|c|c|c|c|c|}
\hline \multirow[b]{2}{*}{ Variables } & \multicolumn{2}{|c|}{$\begin{array}{c}\text { Model 3A } \\
\text { T1Gym SC } \\
\text { Gym skill }\end{array}$} & \multicolumn{2}{|c|}{$\begin{array}{c}\text { Model 3B } \\
\text { T2Gym SC }\end{array}$} & \multicolumn{2}{|c|}{$\begin{array}{c}\text { Model 3C } \\
\Delta \mathrm{T} 2 \mathrm{Gym} \text { SC }\end{array}$} \\
\hline & Effect & SE & Effect & SE & Effect & SE \\
\hline \multicolumn{7}{|l|}{ Fixed effect } \\
\hline Gender & $.28^{*}$ & .04 & $.18^{*}$ & .04 & -.02 & .03 \\
\hline Age & -.04 & .06 & .08 & .06 & $.10^{*}$ & .04 \\
\hline Age $\times$ Gender & .05 & .04 & .06 & .04 & .03 & .03 \\
\hline Individ Gym skills & $.59^{*}$ & .04 & $.61^{*}$ & .04 & $.18^{*}$ & .04 \\
\hline Class-Avg gym skill & $-.46^{*}$ & .20 & $-.68^{*}$ & .19 & $-.35^{*}$ & .12 \\
\hline T1 Gym SC & & & & & $.72 *$ & .03 \\
\hline Constant & .01 & .07 & -.01 & .06 & .01 & .04 \\
\hline \multicolumn{7}{|l|}{ Residual Variance components } \\
\hline Level 2 Class & .06 & .03 & .04 & .02 & .01 & .01 \\
\hline Level 1 Students & $.64 *$ & .05 & $.65^{*}$ & .05 & $.32 *$ & .02 \\
\hline
\end{tabular}

Note. All outcome and predictor variables were standardized $(M=0, S D=1)$ at the individual student level.

Individ Gym Skill = Objective measure of gymnastic skills of individual students; Class-Avg Gym Skill = Classaverages of objective measures of gymnastic skills of individual students (the BFLPE, shaded for clarity); T1Gym SC and T2Gym SC = Gymnastic self-concept measured at the start and end of the program; $\Delta \mathrm{T} 2 \mathrm{Gym}$ $\mathrm{SC}=\mathrm{T} 2$ self-concept controlling for the effect of $\mathrm{T} 1$ self-concept. All parameter estimates are statistically significant when they differ from zero by more than two standard errors (SEs). Analyses are based on responses by 405 students from 20 classes. 
Table 3

The Generality of the Big Fish-Little-Pond Effect (BFLPE): Interactions Between Class-Average Gymnastics Skills, Gender, Age, and Individual Gymnastics Skills.

\begin{tabular}{|c|c|c|c|c|c|c|}
\hline \multirow[b]{2}{*}{ Variables } & \multicolumn{2}{|c|}{$\begin{array}{l}\text { Model 4A } \\
\text { T1Gym SC }\end{array}$} & \multicolumn{2}{|c|}{$\begin{array}{c}\text { Model 4B } \\
\text { T2Gym SC }\end{array}$} & \multicolumn{2}{|c|}{$\begin{array}{c}\text { Model 4C } \\
\Delta \mathrm{T} 2 \mathrm{Gym} \text { SC }\end{array}$} \\
\hline & Effect & SE & Effect & $\mathrm{SE}$ & Effect & $\mathrm{SE}$ \\
\hline \multicolumn{7}{|l|}{ Fixed effect } \\
\hline Gender & $.28 *$ & .04 & $.18^{*}$ & .04 & -.02 & .03 \\
\hline Age & -.04 & .06 & .08 & .06 & $.11^{*}$ & .04 \\
\hline Age $\times$ Gender & .04 & .05 & .03 & .05 & .00 & .03 \\
\hline Individ Gym skills & $.59 *$ & .04 & $.61 *$ & .04 & $.19^{*}$ & .04 \\
\hline Class-Avg gym skill (CAGS) & $-.53 *$ & .22 & $-.70^{*}$ & .21 & $-.35^{*}$ & .13 \\
\hline CAGS $\times$ Gender & .00 & .15 & .15 & .15 & .15 & 11 \\
\hline CAGS $\times$ Age & .14 & .16 & .04 & .16 & -.04 & .10 \\
\hline CAGS $\times$ Individ Gym skills & .00 & .13 & -.02 & .13 & -.03 & .09 \\
\hline T1 Gym SC & & & & & $.72 *$ & .03 \\
\hline Constant & .04 & .07 & -.01 & .07 & .01 & .04 \\
\hline \multicolumn{7}{|l|}{ Residual Variance components } \\
\hline Level 2 Class & .05 & .03 & .04 & .02 & .01 & .01 \\
\hline Level 1 Students & $.63^{*}$ & .05 & $.64 *$ & .05 & $.32 *$ & .02 \\
\hline
\end{tabular}

Note. All outcome and predictor variables were standardized $(M=0, S D=1)$ at the individual student level. Individ Gym Skills = Objective measures of gymnastic skills of individual students; Class-Avg Gym Skill $($ CAGS $)=$ Class-averages of objective measures of gymnastic skills of individual students (the BFLPE, shaded for clarity); T1Gym SC and T2Gym SC = Gymnastic self-concept measured at the start and end of the program; $\Delta \mathrm{T} 2 \mathrm{Gym} \mathrm{SC}=\mathrm{T} 2$ self-concept controlling for the effect of T1 self-concept. CAGS Gym $\times$ Gender, CAGS Gym $\times$ Age, and CAGS Gym $\times$ Ind Gym skills $=$ interactions between class-average gymnastic skills with gender, age, and individual gymnastic skills respectively. All parameter estimates are statistically significant when they differ from zero by more than two standard errors (SEs). Analyses are based on responses by 405 students from 20 classes. 

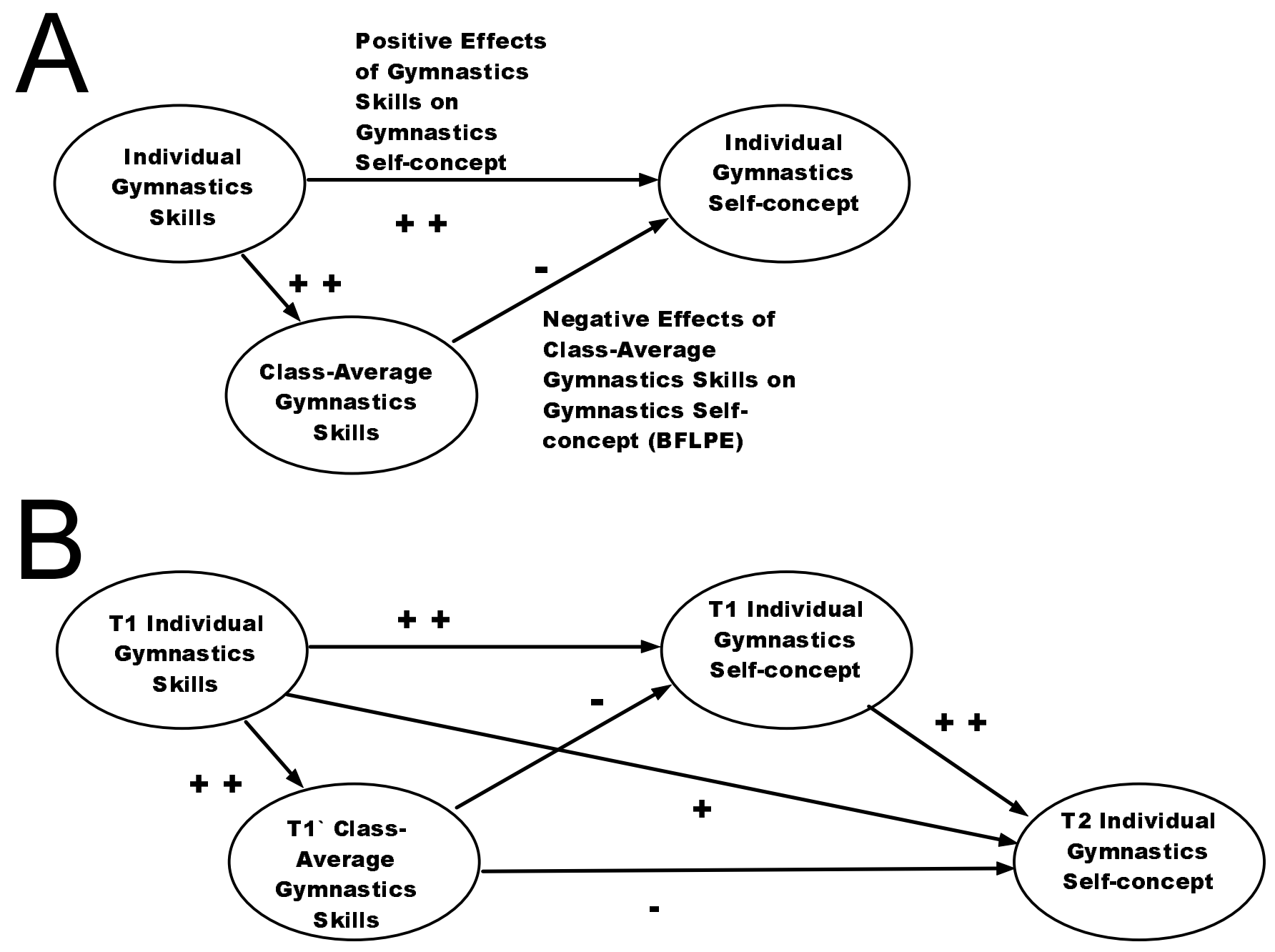